\title{
Defining Scheduling Problems for Key Resources in Energy-Efficient Port Service Systems
}

\author{
Daofang Chang, Ting Fang, Junliang He, and Danping Lin \\ Institute of Logistics Science and Engineering, Shanghai Maritime University, 1550 Haigang Avenue, Shanghai 201306, China \\ Correspondence should be addressed to Ting Fang; fangting_china@126.com
}

Received 7 August 2016; Accepted 31 August 2016

Academic Editor: Si Zhang

Copyright ( 2016 Daofang Chang et al. This is an open access article distributed under the Creative Commons Attribution License, which permits unrestricted use, distribution, and reproduction in any medium, provided the original work is properly cited.

\begin{abstract}
This paper addresses the problem of key resource scheduling of container terminals for energy-efficient operation. A combination of key resource scheduling and energy-efficient operation in container terminals is firstly described. An energy-efficient evaluation model of the key resource scheduling is then proposed. The objective set, decision variable set, and constraint set of key resource scheduling of a container terminal for energy-efficient operation are established in this paper. At the same time, their mapping relationship is carefully analyzed and the system structure of the key resource scheduling for energy-efficient operation of a container terminal is finally proposed.
\end{abstract}

\section{Introduction}

The key resources in a container terminal usually include a berth, quay cranes, a storage yard, and yard cranes, as shown in Figure 1. Their scheduling must be proposed in advance for coordination with container shipping lines that transport containers on regularly scheduled service routes [1]. These key resources work together to load and unload containers. Although this adds some value, it is also the main contributor to energy consumption and environmental pollution. To obtain low energy consumption, high efficiency, and better benefits, port workers have designed some effective scheduling schemes for berths, quay cranes, storage yards, and yard cranes. These activities improve the operation process of the container terminal and ensure that each link of the operation is environmentally friendly, which fundamentally changes the opportunities and modes for current ports to seek throughput growth development. Energy-efficient operation of the container terminal is not a negative feature of production operation in traditional terminals but rather complements its development. Energy-efficient operation has encouraged the production operation process of container terminals to become more environmentally friendly.

"Energy efficiency" is also regularly called "efficient energy use" at an international level, and, together with a renewable energy policy, these are considered to be the two pillars of future sustainable energy policies [2]. In the field of academic research into energy efficiency, physicist Lovins proposed the concept of a soft energy path which is closely related to energy efficiency [3]. Researchers in the US Department of Energy have studied an "energy-efficient distribution system" (REEDS) and found 90 billion kilowatts of energy saving. In the energy efficiency related international industry, the minimum energy efficiency standards and regulations of the European Union have come into force in Zurich, Switzerland. This is a milestone for the EU in promotion of energy efficiency of low-voltage motors [4].

Container terminals act as an important hub for global economic and trade activities and are facing increasing environmental pressure [5]. At a container terminal design level, ZPMC have used the experience of HHLA container terminals based on AGVs [6] and PSA container terminals based on high capacity storage [7] to propose a new container terminal based on a frame bridge. This is the first international energy-efficient port scheme that is based on mechanical and electrical integration technology.

Within the industry, model programming problems have been studied by many scholars. Wang proposed a novel hybrid-link-based model that nests existing origin-linkbased and destination-link-based models as special cases [8]. 


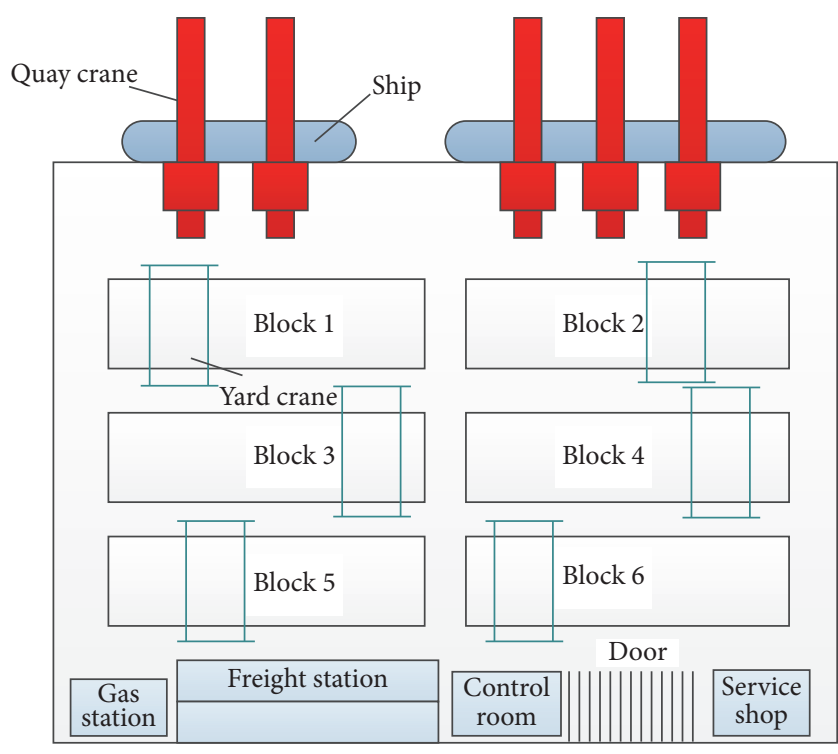

FIgURE 1: Key resources of a container terminal.

Additionally, Wang proposed a global optimization approach that is suitable for bilevel programming models with finite discrete upper-level decision variables. A conic quadratic mixed-integer linear programming approach was also developed to solve relaxed models of bilevel formulation of speed limit designs [9]. Qu et al. highlighted that the inaccuracy of single-regime models is not caused solely by their functional forms, but also by the sample selection bias. They also applied a weighted least squares method (WLSM) that addresses the sample selection bias problem [10]. Qu et al. discovered that the follow-up time is indeed significantly affected by the traffic volume, the number of vehicles that are waiting behind, the vehicle type, and the drivers' gender. An inverse Gaussian regression model was also further developed in order to establish a relationship between the follow-up time and its contributing factors [11].

The scheduling problems of key resources in container terminals have gradually become a hot topic in academia and industry [12]. There has been a lot of research into scheduling space and equipment resources and operational performance optimization in container terminals. For integrated scheduling of berths and quay cranes, Imai et al. developed a dynamic method for berth scheduling based on discrete berths which reduces the working time of ship 5 [13]. Kim and Moon proposed a scheduling method for berths based on the shortest delay time of the ship leaving a port using a simulated annealing algorithm [14]. Additionally, Park and Kim adopted a gradient algorithm to study berth scheduling methods [15]. Guan et al. designed a heuristic algorithm for berth scheduling processing to ensure that ships spend the shortest time possible at the terminal [16]. Chang et al. developed a method to combine the heuristic algorithm and simulation to solve the scheduling problem for a combination of berths and quay cranes [17]. Legato and Mazza studied the problem of vessel arrival, berthing, and leaving using a queuing theory method [18]. The main goal of all of these studies was to reduce the time that the ship spends berthed while also decreasing the cost of berthing. For yard scheduling, many researchers have undertaken thorough research into the overall yard distribution of import and export containers. Zhang et al. designed a storage model to balance the number of containers loaded and unloaded in each block to achieve the shortest horizontal transport distance across the yard [19]. Chen et al. proposed a hybrid method that combines the Tabu search algorithm with an optimization algorithm to solve the yard scheduling problem [20]. Therefore, yard scheduling has currently been the research priority for export containers. Some problems still exist for yard scheduling, such as the scale of the models and low solution efficiencies. For yard crane scheduling, many researchers have aimed to achieve high efficiency in the yard. Linn et al. established a scheduling model for yard cranes based on integer programming [21]. Additionally, there are many other similar methods in this area.

Although current researchers have made certain progress in key resource scheduling of container terminals, an energyefficient and integrated scheduling method has not been effectively proposed. Therefore, there is no complete integration of key resources scheduling systems nor any efficiency study including the objective set, the decision-making variable set, and the constraint set which defines the mapping relationship between them. In this paper, an integrated key resource scheduling system will be designed and the mapping relationship of the objective set, the decision-making variable set, and the constraint set will be defined.

In Section 2, an energy-efficient evaluation model of the key resource scheduling will be proposed. In Section 3, the objective set, decision variable set, and constraint set of key resource scheduling of a container terminal for energy-efficient operation are established and their mapping relationship is carefully analyzed. The system structure of the key resource scheduling for energy-efficient operation in the container terminal will finally be proposed. Conclusions will be given in Section 4 .

\section{An Energy-Efficient Evaluation Model}

Energy-efficient scheduling of various types of core resources is the key to energy-efficient operation of a container terminal. A container terminal includes four types of key resources: a berth, quay cranes, a storage yard, and yard cranes. Obviously the berth and storage yard are spatial resources, and the quay cranes and yard cranes are equipment resources. In contrast with general resource scheduling problems, the efficient scheduling of resources needs to consider not only the efficiency of the allocations but also the evaluation index of the energy consumption.

In this paper, efficient operation of the container terminal requires efficient scheduling of the four key resources: the berth, the quay cranes, the storage yard, and the yard cranes. The scheduling of each of these four types of key resources depends on each other. The scheduling results of one type of resource may provide the initial conditions for the scheduling of another type of resource. At the same time, the results of scheduling the second resource type may have an impact on scheduling of other resources. 
2.1. Parameter Setting. In this section, the parameters are defined as follows:

CT: the time delay of the ship leaving the port.

BT: the berthing time of the ship.

DT: the planned departure time of the ship.

ST: the loading and unloading time of the quay crane.

$D$ : the offset of the berthing position $(\mathrm{m})$.

$P$ : the actual berthing position.

$P^{*}$ : the planned berthing location.

$\mathrm{TE}^{s}$ : energy consumption of ships at the port.

$\varepsilon$ : energy consumption of ships per unit of time at the port.

$n$ : total number of quay cranes allocated to the ship.

$\mathrm{qn}_{i}$ : loading and unloading quantity for the $i$ th quay crane.

$\eta$ : the handling efficiency of the quay crane.

$g$ : efficiency coefficient when multiple quay cranes are working.

$s_{i}$ : starting working time of the $i$ th quay crane.

$\mathrm{TE}^{q}$ : energy consumption of the quay crane.

$\rho$ : energy consumption of the quay crane per unit of time.

Td: horizontal transport distance.

$b$ : blocks allocated to the ship.

$\mathrm{bn}_{i}$ : the number of containers allocated to the $i$ th block.

$d_{i}$ : horizontal transport distance between the berth and the $i$ th block.

BP: economic balance between the blocks.

$\mathrm{bn}_{i}$ : the handling quantity allocated to the $i$ th block.

Bayd: the distance between two bays.

$\mathrm{ba}^{i}$ : the number of bays allocated to the $i$ th block.

$P_{i j}$ : the position of the $j$ th bay in the $i$ th block.

Bs: the continuity of bays in the block.

$g_{i j k}$ : the serial number of the $j$ th bay and $k$ th roll in the $i$ th block.

Lpb: the parallelism of the sending containers.

bnlp $_{i}$ : the sum of the allocated blocks in the $i$ th port.

lp: the number of the port discharge.

$\mathrm{TE}^{t}$ : energy consumption of horizontal transport.

$\lambda$ : energy consumption of the truck per unit distance.

DT: the delay time of the task group.

tn: the number of the task group.

$\mathrm{ST}_{i j}$ : starting working time of yard crane $j$.

$\mathrm{NT}_{i j}$ : the allocated handling quantity of yard crane $j$ in task group $i$.
$\mathrm{Et}_{i}^{p}$ : the planned completion time of task group $i$.

$\sigma$ : the loading and unloading efficiency of the yard crane.

ny: the total number of yard cranes.

TM: the total time of yard cranes to move from one block to another.

$t_{i i^{\prime}}$ : time for a yard crane to move from task group $i$ to task group $i^{\prime}$.

$\mathrm{TE}^{y}$ : the moving energy consumption of the yard cranes.

$\mathrm{Ls}_{i j k}$ : the current position of yard crane $j$ for task $k$ in task group $i$.

$\mathrm{Lt}_{i j k}$ : target position of yard crane $j$ for task $k$ in task group $i$.

$\mathrm{vt}_{j}$ : quantity of task group $i$.

$\omega$ : energy consumption of yard crane per unit distance.

$\mathrm{TE}^{y}$ : the energy consumption of the yard crane.

$\mu$ : the handling energy consumption of the yard crane per unit time.

2.2. Efficiency Evaluation for Berth Scheduling. Primarily, the scheduling of a berth requires decisions to be made on the berthing location and the berthing time of ships. There are many factors that can impact the results, including the ship specifications, the ship arrival time, the loading and unloading quantity required for each ship, the currently moored ships, and the length of each shoreline ship on the berth. In this efficiency evaluation model, the objectives used for making a decision are to ensure that a ship is at port for the shortest possible time while maintaining the lowest possible energy consumption for the ship at port and the shortest horizontal transport distance. The calculation models for energy consumption and efficiency evaluation for berth scheduling can be illustrated as follows.

(1) Efficiency Calculation: Equation for Berth Scheduling. The time delay of a ship leaving a port is calculated using (1) and the offset of the berthing:

$$
\begin{aligned}
\mathrm{CT} & =\mathrm{ST}+(\mathrm{BT}-\mathrm{DT}) \\
D & =P-P^{*}
\end{aligned}
$$

(2) Energy Consumption Calculation: Equation for Berth Scheduling. The energy consumption of a ship at a port is determined by its turnaround time. The turnaround time of a ship is determined by the ship's berthing time and departure time, which is within the category of berth scheduling. The energy consumption of a ship at port is calculated using

$$
\mathrm{TE}^{\mathcal{S}}=\mathrm{CT} \cdot \varepsilon
$$


2.3. Efficiency Evaluation for Quay Crane Scheduling. The scheduling of quay cranes depends mainly on the time when each quay crane starts service and the distribution of each quay crane. There are many factors that need to be considered, including the number of quay cranes, the current position of each quay crane, the current state of each quay crane, the shipping carts, the efficiency of each quay crane, and the energy consumption of each quay crane per unit of time. In this paper, the objectives that are used for decision-making are based on obtaining the shortest service time of ships and the minimum energy consumption of quay cranes during loading and unloading operations.

(1) Efficiency Calculation: Equation for Quay Crane Scheduling. The service time of a ship ends once loading and unloading operations have been completed at the quay side. The acceptable service time of the ship is calculated as follows:

$$
\mathrm{ST}=\underset{\{i=1,2, \ldots, n\}}{\operatorname{Max}}\left(\frac{\mathrm{st}_{i}+\mathrm{qn}_{i}}{\left(\eta /(n)^{g}\right)}\right)-\mathrm{BT} .
$$

(2) Energy Consumption Calculation: Equation for Quay Crane Scheduling. Equation (5) gives the energy consumption calculation equation for quay crane scheduling as follows:

$$
\mathrm{TE}^{q}=\sum_{i=1}^{n} \mathrm{qn}_{i} \cdot\left(\frac{\eta}{(n)^{g}}\right) \cdot \rho
$$

2.4. Efficiency Evaluation for Yard Scheduling. Generally, the scheduling of a yard includes scheduling blocks and bays. There are some additional factors that have an impact on the scheduling of a yard, such as the loading and unloading of the ship, the division of blocks, the location of blocks, the position of the berthing ship, and the availability of the blocks in the container terminal. The objectives used for decisionmaking are mainly based on achieving the shortest horizontal transportation distance, the highest economic balance of the blocks, the shortest moving distance of the yard cranes, and the minimum energy consumption for the horizontal transportation.

(1) Efficiency Calculation: Equation for Yard Scheduling. Equation (6) can be used to obtain the horizontal transportation distance as follows:

$$
\mathrm{Td}=\sum_{i=1}^{b} \mathrm{bn}_{i} \cdot d_{i}
$$

For yard scheduling, there are two factors that influence the moving distance of a yard crane: the concentration of bays in a block and the continuity of the block in the bay. Therefore, calculation of the moving distance of a yard crane can be broken down into two steps. The first step is the calculation of the distance between distributed bays and the second step is calculation of the continuity assigned to the bay in the container terminal. In (7), the economic balance between blocks is calculated. The economic balance between blocks is based on the difference in production value between the allocated blocks with the largest and smallest production values. As shown in (8), the distance between bays is included in the calculations. The continuity that is assigned to a bay in the container terminal is expressed by (9):

$$
\begin{aligned}
& \mathrm{BP}=\operatorname{Max}_{\{i=1,2, \ldots, b\}}\left(\mathrm{bn}_{i}\right)-\underset{\{i=1,2, \ldots, b\}}{\operatorname{Min}}\left(\mathrm{bn}_{i}\right) \\
& \text { Bayd }=\sum_{i=1}^{b} \sum_{j=2}^{\text {ba }^{i}}\left(P_{i j}-P_{i(j-1)}\right) \\
& \mathrm{Bs}=\sum_{i=1}^{b} \sum_{j=1}^{\mathrm{ba}} \sum_{k=1}^{l^{i j}}\left|f_{i j k}-1\right| \text {, } \\
& f_{i j k}= \begin{cases}\frac{g_{i j k}-g_{(i j k-1)}}{\left|g_{i j k}-g_{(i j k-1)}\right|}, & \text { if } g_{i j k} \neq g_{(i j k-1)} \\
1, & \text { otherwise. }\end{cases}
\end{aligned}
$$

The continuity of the sending containers can be evaluated based on the continuity assigned to the bay. The parallelism between the sending containers is mainly determined based on whether the distribution of blocks in the same port is scattered or not, as shown in

$$
\mathrm{Lpb}=\sum_{i=1}^{\mathrm{lp}} \mathrm{bnlp}_{i}
$$

(2) Energy Consumption Calculation: Equation for Yard Scheduling. The energy consumption of horizontal transportation is shown in

$$
\mathrm{TE}^{t}=\mathrm{Td} \cdot \lambda
$$

2.5. Efficiency Evaluation for Yard Crane Scheduling. The scheduling of yard cranes requires decision-making on the task group needing service, the start time of that service, and the number of containers to be loaded and unloaded for that service. There are many factors impacting this scheduling, including the block and bay of the task group, the handling efficiency of the yard crane, the current position of the yard crane, and the number of yard cranes. The objectives for decision-making are mainly based on achieving the minimum delay in completing a task group, the minimum number of transitions of yard cranes, and the minimum energy consumption of yard cranes during both moving and handling.

(1) Efficiency Calculation: Equation for Yard Crane Scheduling. The time delay in finishing a task group is described by (12) and the transition time of yard cranes is described by (13):

$$
\mathrm{DT}=\sum_{i=1}^{\mathrm{tn}}\left(\underset{\{j=1,2, \ldots, \mathrm{ny}\}}{\operatorname{Max}}\left(\mathrm{ST}_{i j}+\mathrm{NT}_{i j} \cdot \sigma\right)-\mathrm{Et}_{i}^{p}\right),
$$




$$
\begin{aligned}
\mathrm{TM} & =\sum_{i=1}^{\mathrm{tn}} \sum_{i^{\prime}=1, i \neq i^{\prime}}^{\mathrm{tn}} \sum_{j=1}^{\mathrm{ny}} s_{i i^{\prime}}^{j} \cdot t_{i i^{\prime}}, \\
s_{i i^{\prime}}^{j} & = \begin{cases}1, & \text { If the task group } i \text { is finished by yard crane } j, \text { then the task group } i^{\prime} \text { will be done right now; } \\
0, & \text { otherwise. }\end{cases}
\end{aligned}
$$

(2) Energy Consumption Calculation: Equation for Yard Crane Scheduling. Equation (14) represents the moving energy consumption of a yard crane and (15) describes the handling energy consumption of a yard crane as follows:

$$
\begin{aligned}
\mathrm{TE}^{y} & =\sum_{i=1}^{\mathrm{tn}} \sum_{j=1}^{\mathrm{ny}^{\mathrm{vt}} \sum_{k=1}}\left|\mathrm{Ls}_{i j k}-\mathrm{Lt}_{i j k}\right| \cdot \omega \\
\mathrm{TE}^{\mathrm{yc}} & =\sum_{i=1}^{\mathrm{ny}} \sum_{j=1}^{\mathrm{tn}} \mathrm{NT}_{i j} \cdot \sigma \cdot \mu .
\end{aligned}
$$

\section{Framework of the Scheduling Model}

In practice, the scheduling of core resources in a container terminal consists of a series of decision-making processes. Decision-making is required for scheduling of the berth, quay cranes, storage yard, and yard cranes. Since the berthing position of ships is required to make decisions on when to implement the scheduling of quay cranes, the loading and unloading time of ships must be considered for quay crane scheduling, which is decided by the berth scheduling. Therefore, integration is required between the scheduling problems for quay cranes and berths. In this paper, they are considered to be a unified problem for the purposes of decision-making and optimization. The decision objectives for the core resource allocation in traditional container terminals are mainly based on time ( $T$, such as the turnaround time of a ship and the delay time of a task group) and distance ( $D$, such as the offset distance of the berthing position, the horizontal transport distance, and the moving distance of the yard crane). In this paper, not only is the efficiency objective taken into consideration but also the energy consumption $(E)$ is taken into consideration.

\subsection{Parameter Setting. The parameters are defined as follows:}

BQ: the decision-making variable set for integrated scheduling of the berth and quay cranes.

BL: the decision-making variable set for yard scheduling.

YC: the decision-making variable set for yard crane scheduling.

TC: the time constraint set.

SC: the space constraint set.

EC: the equipment constraint set.

3.2. Modeling of the Objective Set. The optimized objective set for efficient scheduling of key resources in a container terminal consists of time $(T)$, distance $(D)$. and energy consumption $(E)$. The mapping relationship between the objective set and the decision-making problem is shown in Figure 2. These three decision-making objectives can be further embodied based on the specific scheduling problem of key resources. In addition, each objective includes a number of independent components. Taking the energy consumption objective $E$ as an example, $E$ includes the energy consumption of ships at port $E_{1}$, the energy consumption of the loading and unloading operations of quay crane $E_{2}$, the energy consumption of horizontal transport $E_{3}$, the energy consumption of moving the yard crane $E_{4}$, and the energy consumption of the loading and unloading operations of the yard crane $E_{5}$. Therefore, each objective can be represented by a vector composed of various factors. For example, $E$ can be expressed as a vector of $n$ subobjects, as shown in (16). In a similar way, the other objectives can be expressed as shown in (17) and (18):

$$
\begin{aligned}
\widetilde{E} & =\left(E_{1}, E_{2}, \ldots, E_{n}\right) \\
\widetilde{T} & =\left(T_{1}, T_{2}, \ldots, T_{n}\right) \\
\widetilde{D} & =\left(D_{1}, D_{2}, \ldots, D_{n}\right) .
\end{aligned}
$$

3.3. Modeling of the Decision Variable Set. The scheduling of key resources in a container terminal consists of multiple optimization decision-making problems, including the integrated scheduling of the berth and quay cranes, yard scheduling, and yard crane scheduling. The decision variables of each decision-making problem are shown in Figure 3.

The decision-making problems of the application can be regarded as being composed of many decision-making subquestions. For this purpose, each decision problem is regarded as a vector. The decision-making variable vector for integrated scheduling of the berth and quay cranes can be indicated by $\mathrm{BQ}=\left\{\mathrm{bq}_{1}, \mathrm{bq}_{2}, \ldots, \mathrm{bq}_{m}\right\}$. Equation (19) shows the decision-making variable set $D$ for the scheduling of key resources within the overall container terminal:

$$
D=\left[\begin{array}{c}
\mathrm{BQ}=\left(\mathrm{bq}_{1}, \mathrm{bq}_{2}, \ldots, \mathrm{bq}_{m}\right) \\
\mathrm{BL}=\left(\mathrm{bl}_{1}, \mathrm{bl}_{2}, \ldots, \mathrm{bl}_{n}\right) \\
\mathrm{YC}=\left(\mathrm{yc}_{1}, \mathrm{yc}_{2}, \ldots, \mathrm{yc}_{k}\right)
\end{array}\right] .
$$

3.4. Modeling of the Constraint Set. In the energy-efficient scheduling decision-making model of key resources in a container terminal, the constraint set is quite complicated. The optimization decision-making model of the constraint set usually includes time constraints, space constraints, and equipment constraints. For example, the berthing time of a 


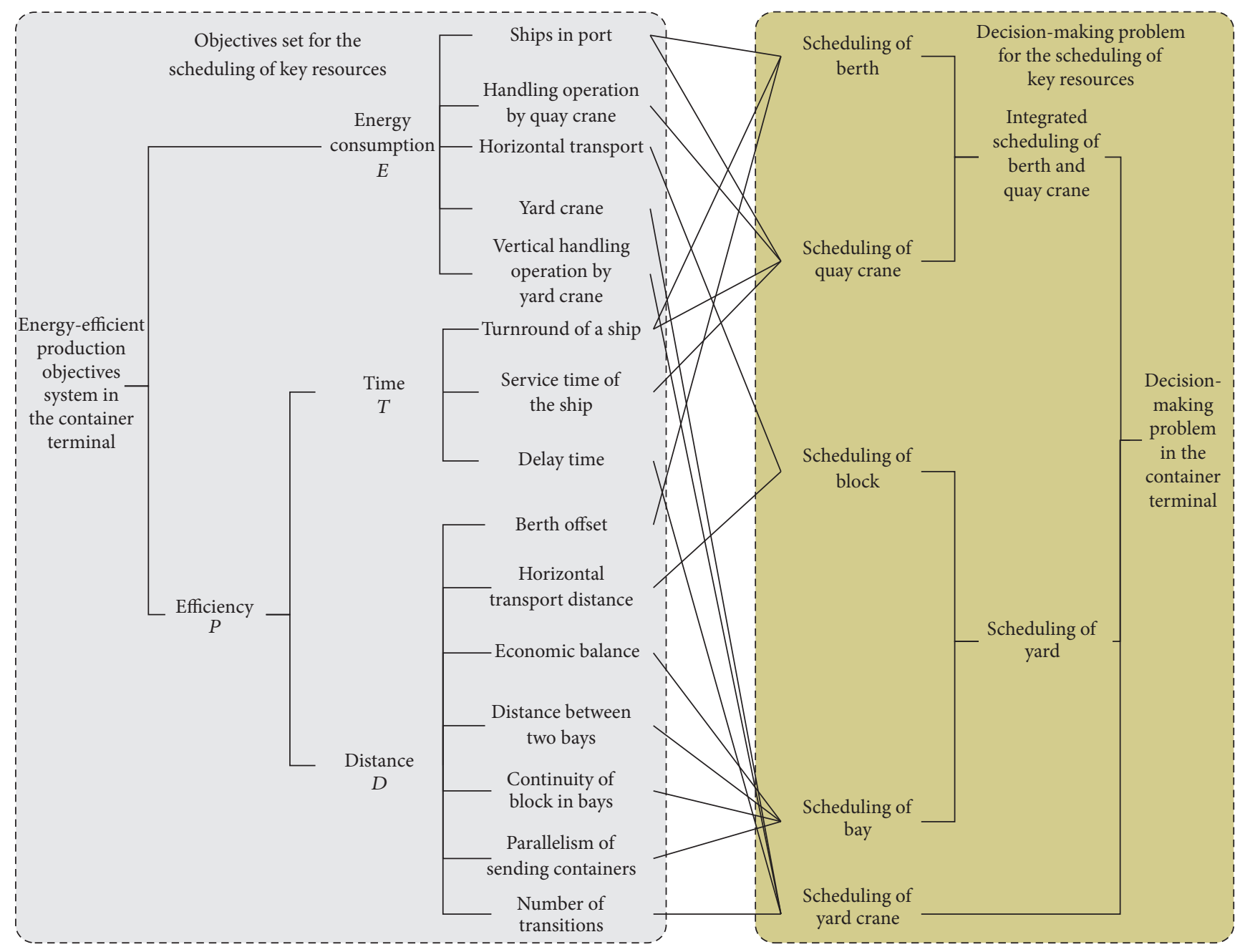

Figure 2: Mapping relationship between the objective set and the decision-making problem set for key resource energy-efficient scheduling of a container terminal.

ship must be greater than or equal to the arrival time of the ship. Then the berthing location of a ship must be within the quay side line. Additionally, the number of assigned quay cranes must be less than or equal to the total number of quay cranes in the wharf. Therefore, the constraint set of the scheduling model can be expressed as $C$ in (20). $C$ is made up of the time constraint set TC, the space constraint set ST, and the equipment constraint set EC. Each constraint is expressed within this equation and the inequality constraints are given in (21):

$$
\begin{aligned}
& C= \quad\left[\begin{array}{l}
\mathrm{TC}=\left(\mathrm{tc}_{1}, \mathrm{tc}_{2}, \ldots, \mathrm{tc}_{m}\right) \\
\mathrm{SC}=\left(\mathrm{sc}_{1}, \mathrm{sc}_{2}, \ldots, \mathrm{sc}_{n}\right) \\
\mathrm{EC}=\left(\mathrm{ec}_{1}, \mathrm{ec}_{2}, \ldots, \mathrm{ec}_{k}\right)
\end{array}\right] \\
& \text { s.t. } \quad C_{u}=0 \\
& \quad C_{v} \leq 0 .
\end{aligned}
$$

3.5. Modeling of Decisions. As previously discussed, in the efficient decision-making scheduling model of key resources, a mapping relationship exists between the decision-making variable set, the constraint set, and the objective set. In this model, the calculation model for the objective functions and the constraint conditions is comprised of decision-making variables and constants. Equation (22) proposes the mapping relationship between the objective set and the decisionmaking variable set. Additionally, the mapping relationship between the constraint set and the decision-making variable set is expressed in (23):

$$
\begin{aligned}
& {\left[\begin{array}{l}
E=E(\mathrm{BQ}, \mathrm{BL}, \mathrm{YC}) \\
T=T(\mathrm{BQ}, \mathrm{BL}, \mathrm{YC}) \\
L=L(\mathrm{BQ}, \mathrm{BL}, \mathrm{YC})
\end{array}\right]} \\
& {\left[\begin{array}{l}
\mathrm{TC}=\mathrm{TC}(\mathrm{BQ}, \mathrm{BL}, \mathrm{YC}) \\
\mathrm{SC}=\mathrm{SC}(\mathrm{BQ}, \mathrm{BL}, \mathrm{YC}) \\
\mathrm{EC}=\mathrm{EC}(\mathrm{BQ}, \mathrm{BL}, \mathrm{YC})
\end{array}\right] .}
\end{aligned}
$$

The mapping relationship between the decision-making variable set, the constraint set, and the objective set in the 


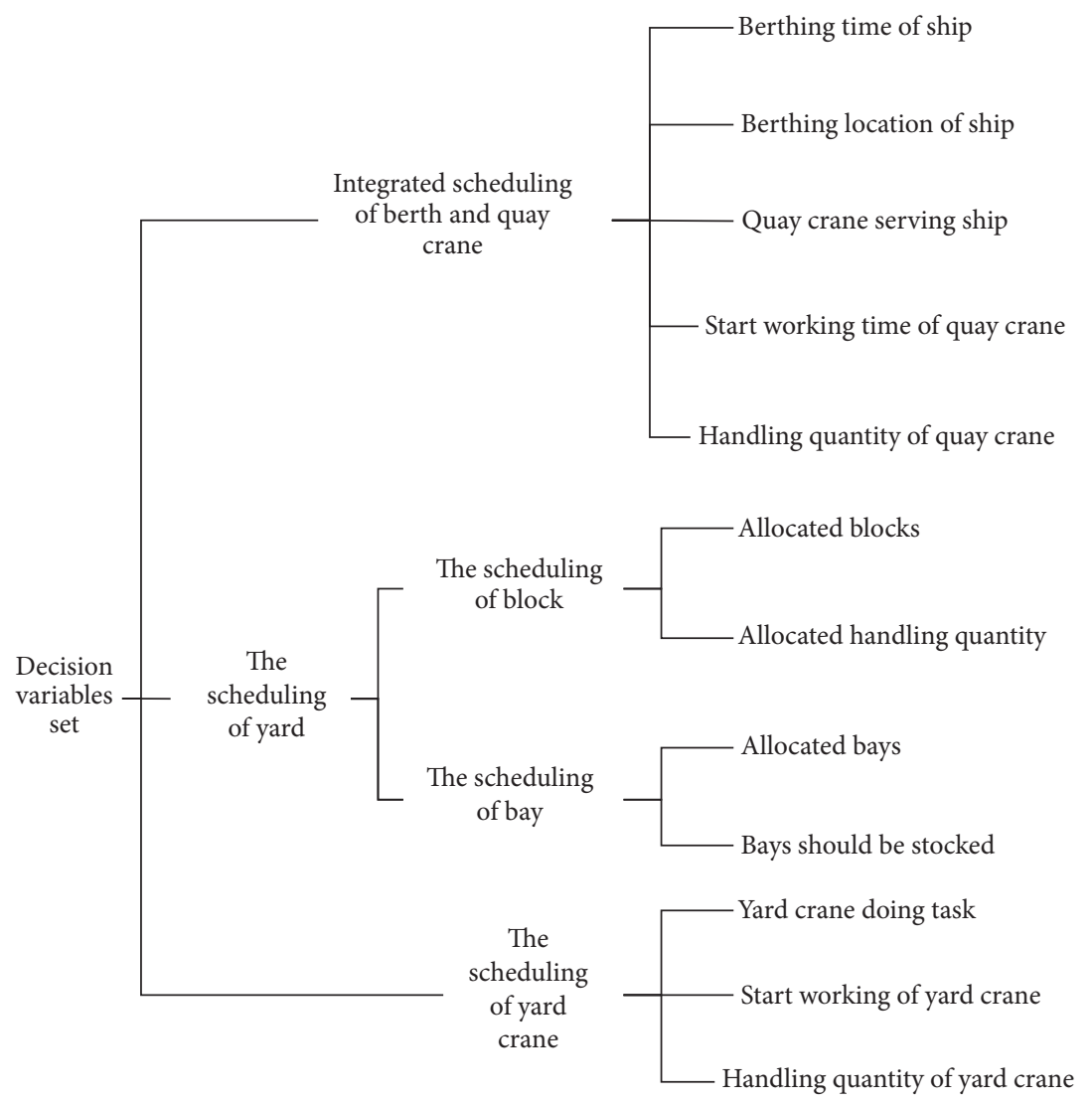

Figure 3: Decision variable set for key resource energy-efficient scheduling of the container terminal.

efficient decision-making scheduling model of key resources in the container terminal is shown in Figure 4. Based on careful discussion of the decision-making variable set, the constraint set, and the objective set, an overall and efficient scheduling model for the core resources was finally obtained, as shown in (24). $\omega_{1}, \omega_{2}$, and $\omega_{3}$ represent the different weights of the objective function in (24):

objective function: $\operatorname{Min} f$

$$
\begin{aligned}
&=\left[\begin{array}{l}
\omega_{1} \cdot E(\mathrm{BQ}, \mathrm{BL}, \mathrm{YC}) \\
\omega_{2} \cdot T(\mathrm{BQ}, \mathrm{BL}, \mathrm{YC}) \\
\omega_{3} \cdot L(\mathrm{BQ}, \mathrm{BL}, \mathrm{YC})
\end{array}\right] \\
& \text { constraint condition: }\left[\begin{array}{c}
\mathrm{TC}_{u}(\mathrm{BQ}, \mathrm{BL}, \mathrm{YC}) \\
\mathrm{SC}_{u}(\mathrm{BQ}, \mathrm{BL}, \mathrm{YC}) \\
\mathrm{EC}_{u}(\mathrm{BQ}, \mathrm{BL}, \mathrm{YC})
\end{array}\right]=0 \\
& {\left[\begin{array}{c}
\mathrm{TC}_{v}(\mathrm{BQ}, \mathrm{BL}, \mathrm{YC}) \\
\mathrm{SC}_{v}(\mathrm{BQ}, \mathrm{BL}, \mathrm{YC}) \\
\mathrm{EC}_{v}(\mathrm{BQ}, \mathrm{BL}, \mathrm{YC})
\end{array}\right] \leq 0 . }
\end{aligned}
$$

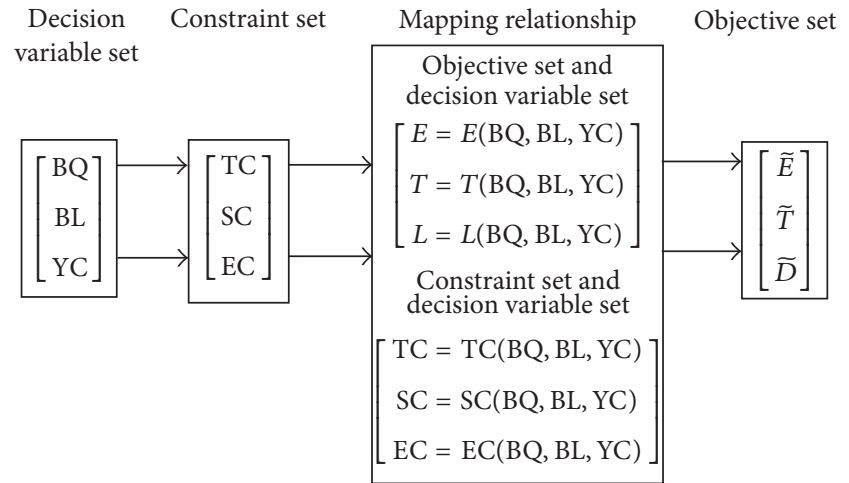

FIGURE 4: Mapping relationship between the objective set, constraint set, and decision variable set for key resource energy-efficient scheduling of a container terminal.

\section{Conclusions}

This paper has firstly described the combination of key resources scheduling and energy-efficient operation in a container terminal. An energy-efficient evaluation model for key resource scheduling has then been proposed. The objective set, decision variable set, and constraint set of key resource 
scheduling of container terminals for energy-efficient operation are then established in this paper. At the same time, their mapping relationship is carefully analyzed and the system structure of the key resource scheduling for energy-efficient operation in a container terminal is finally proposed.

In future studies, we will establish an efficient operation process analysis framework for container terminals, and subdivision of the evaluation objective will be studied on this basis. In addition, an evaluation index system for an efficient operation process will be established which will include carbon load properties.

\section{Competing Interests}

The authors declare that they have no competing interests.

\section{Acknowledgments}

This work was supported by funding from Shanghai Science and Technology Committee (16DZ2349900, 16DZ1201402, 16DZ2340400, 16040501500, 15590501700, 14DZ2280200, and 14170501500), National Natural Science Foundation of China (61540045 and 71602114), Shanghai Municipal Education Commission (14CG48), and Shanghai Talent Development Fund.

\section{References}

[1] S. Wang, X. Qu, and Y. Yang, "Estimation of the perceived value of transit time for containerized cargoes," Transportation Research Part A: Policy and Practice, vol. 78, pp. 298-308, 2015.

[2] B. Prindle, M. Eldridge, M. Eckhardt, and A. Frederick, "The twin pillars of sustainable energy: synergies between energy efficiency and renewable energy technology and policy," 2008, http://aceee.org/.

[3] A. B. Lovins, "Energy strategy: the road not taken?" Foreign Affairs, vol. 55, no. 1, pp. 65-96, 1976.

[4] S. Breukers and E. Heiskanen, "Interaction schemes for 16 successful demand-side management," Deliverable 5 of the Changing Behaviour project, Funded by the EC, 2009.

[5] IMC Services, "Strategic planning and port operations planning," Tech. Rep., IMC Services, Paitilla, Panama, 2009.

[6] M. Grunow, H.-O. Günther, and M. Lehmann, "Strategies for dispatching AGVs at automated seaport container terminals," OR Spectrum, vol. 28, no. 4, pp. 587-610, 2006.

[7] D. Briskorn, A. Drexl, and S. Hartmann, "Inventory-based dispatching of automated guided vehicles on container terminals," OR Spectrum, vol. 28, no. 4, pp. 611-630, 2006.

[8] S. Wang, "A novel hybrid-link-based container routing model," Transportation Research Part E: Logistics and Transportation Review, vol. 61, pp. 165-175, 2014.

[9] S. Wang, "Efficiency and equity of speed limits in transportation networks," Transportation Research Part C: Emerging Technolo gies, vol. 32, pp. 61-75, 2013.

[10] X. Qu, S. Wang, and J. Zhang, "On the fundamental diagram for freeway traffic: a novel calibration approach for single-regime models," Transportation Research Part B: Methodological, vol. 73, pp. 91-102, 2015.

[11] X. Qu, J. Zhang, S. Wang, and Z. Liu, "Modelling follow up time at a single-lane roundabout," Journal of Traffic and Transportation Engineering, vol. 1, no. 2, pp. 97-102, 2014.
[12] D. Steenken, S. Voß, and R. Stahlbock, "Container terminal operation and operations research-a classification and literature review," OR Spectrum, vol. 26, no. 1, pp. 3-49, 2004.

[13] A. Imai, E. Nishimura, and S. Papadimitriou, "The dynamic berth allocation problem for a container port," Transportation Research Part B: Methodological, vol. 35, no. 4, pp. 401-417, 2001.

[14] K. H. Kim and K. C. Moon, "Berth scheduling by simulated annealing," Transportation Research Part B: Methodological, vol. 37, no. 6, pp. 541-560, 2003.

[15] K. T. Park and K. H. Kim, "Berth scheduling for container terminals by using a sub-gradient optimization technique," Journal of the Operational Research Society, vol. 53, no. 9, pp. 1054-1062, 2002.

[16] Y. Guan, W.-Q. Xiao, R. K. Cheung, and C.-L. Li, "A multiprocessor task scheduling model for berth allocation: heuristic and worst-case analysis," Operations Research Letters, vol. 30, no. 5, pp. 343-350, 2002.

[17] D. Chang, W. Yan, C.-H. Chen, and Z. Jiang, "A berth allocation strategy using heuristics algorithm and simulation optimisation," International Journal of Computer Applications in Technology, vol. 32, no. 4, pp. 272-281, 2008.

[18] P. Legato and R. M. Mazza, "Berth planning and resources optimisation at a container terminal via discrete event simulation," European Journal of Operational Research, vol. 133, no. 3, pp. 537-547, 2001.

[19] C. Q. Zhang, J. Y. Liu, Y.-W. Wan, K. G. Murty, and R. J. Linn, "Storage space allocation in container terminals," Transportation Research Part B: Methodological, vol. 37, no. 10, pp. 883-903, 2003.

[20] P. Chen, Z. H. Fu, and L. Adrew, “The yard allocation problem," in Proceedings of the 18th National Conference on Artificial Intelligence, pp. 56-65, Edmonton, Canada, 2002.

[21] R. Linn, J.-Y. Liu, Y.-W. Wan, C. Zhang, and K. G. Murty, "Rubber tired gantry crane deployment for container yard operation," Computers \& Industrial Engineering, vol. 45, no. 3, pp. 429-442, 2003. 

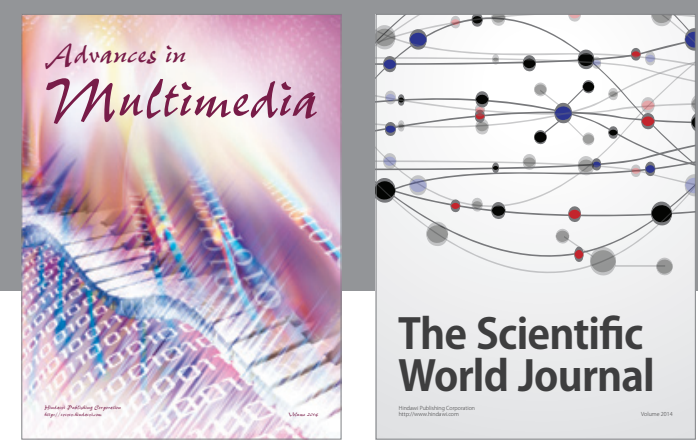

The Scientific World Journal
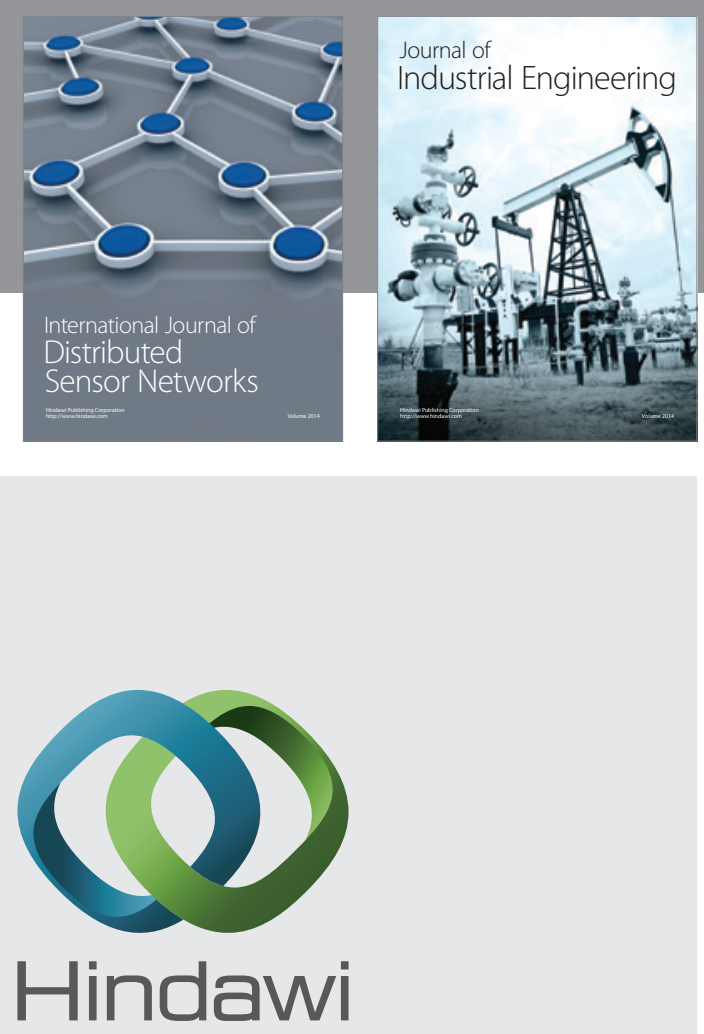

Submit your manuscripts at

http://www.hindawi.com

\section{Computer Networks} and Communications
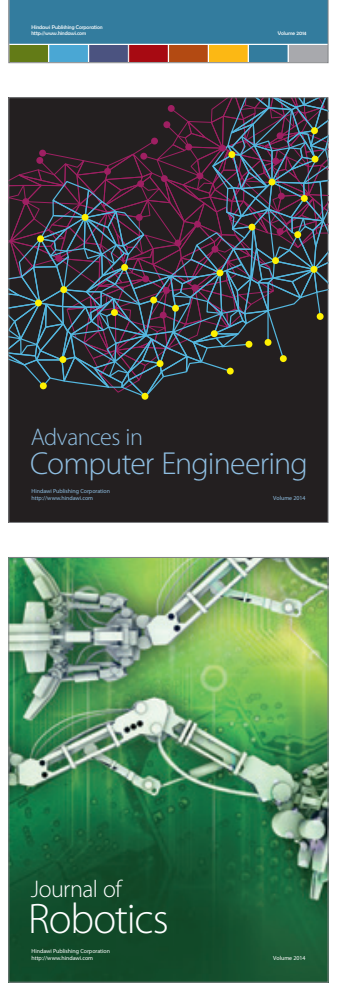
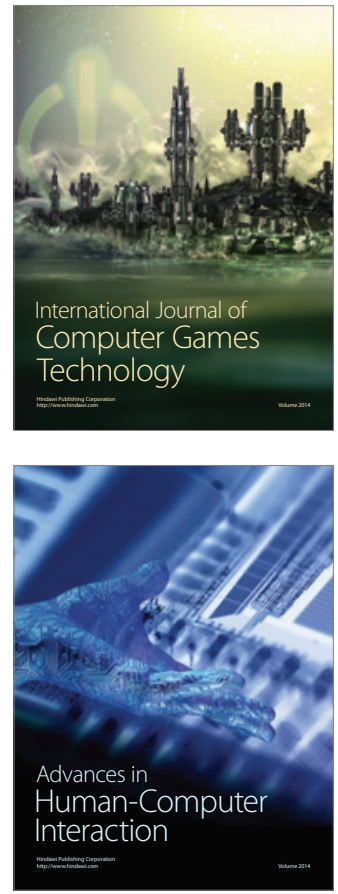
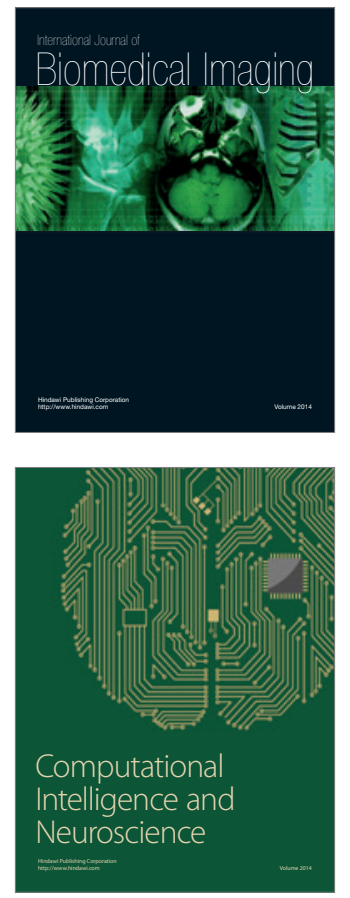
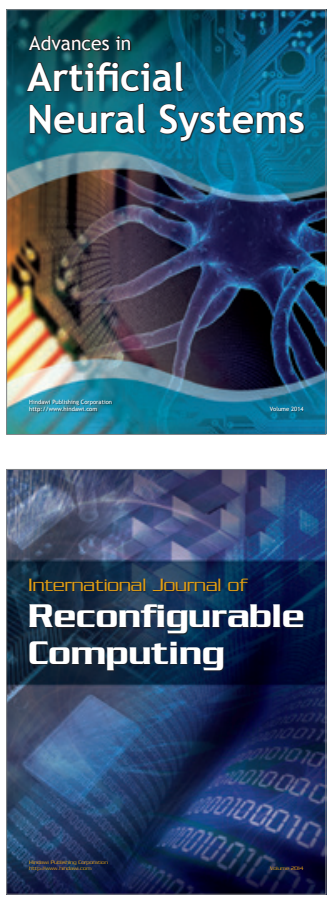
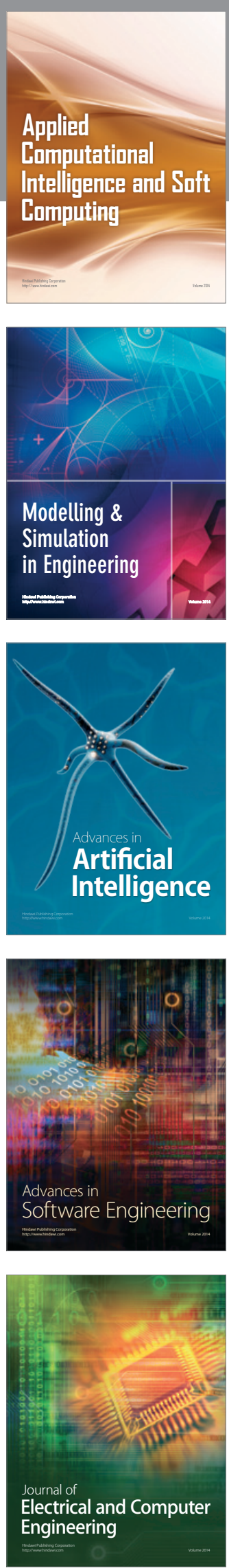